\title{
Reconocimiento póstumo al profesor Joan Pagés Blanch
}

\author{
Ignacio Rojas Rubio, Rodrigo Hidalgo Dattwyler, Sasha Rincón Quiroz, \\ Voltaire Alvarado Peterson, Juan Camilo Álvarez Naranjo, \\ Oliver Meseguer Ruiz, Xenia Fuster Farfán y Fabián Lizana Vásquez.
}

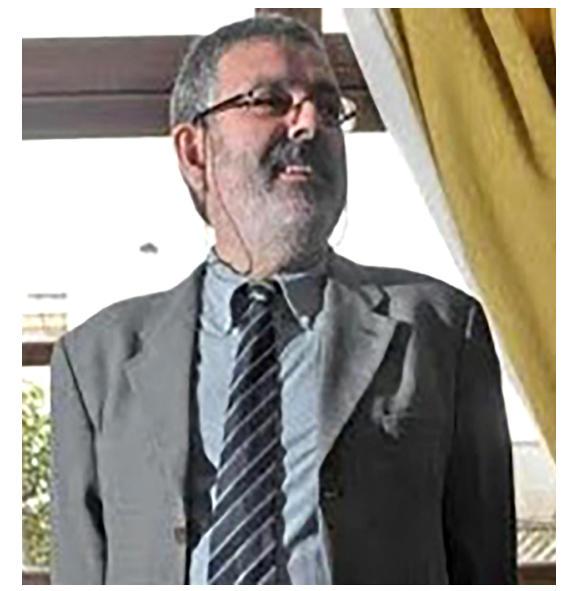

Queremos iniciar la Editorial del Número 79 de la Revista de Geografía Norte Grande haciendo un homenaje al profesor Dr. Joan Pagés Blanch quien nos dejó físicamente en el año 2020. El profesor Pagés fue un destacado investigador en el área de la didáctica de las Ciencias Sociales, especialmente en la Historia y la Geografía. Su formación como licenciado en Filosofía y Letras (especializado en Historia moderna y contemporánea por la Universidad de Barcelona en el año 1972) y como Doctor en Ciencias de la Educación (Universidad Autónoma de Barcelona, 1993) le llevaron a tener una mirada inter y transdisciplinaria, aportando con una amplia publicación de artículos, capítulos y libros.

En sus publicaciones se cuestiona constantemente sobre la epistemología de la historia, la enseñanza y el aprendizaje en las Ciencias Sociales, el currículum escolar, la didáctica del conocimiento, la formación del profesorado, entre otros temas en los cuales trabajó. Tuvo una especial cercanía con América Latina, su segundo hogar, donde hoy se encuentran muchos/as investigadores/as formados/as bajo su magisterio. Por esto, es un honor para nuestra revista contar con uno de los últimos artículos publicados en el que participa el Dr. Joan Pagés Blanch, en el cual escribe junto a la autora Evelyn Viviana Ortega Rocha, y que lleva por nombre: "La formación de la conciencia geográfica en el aula. Estudio de casos en educación secundaria en Chile"

El artículo hace referencia a los desafíos que debe asumir el profesorado para desarrollar una conciencia geográfica para que niños/as y jóvenes comprendan los cambios espaciales para actuar sobre los problemas que nos afectan en aspectos territoriales y ambientales. Para lograr este objetivo, se analizaron entrevistas y observaciones de aula de cinco docentes chilenos del área de historia y geografía. El resultado expuesto nos presenta un análisis crítico de la situación de enseñanza-aprendizaje situada en el enfoque descriptivo-técnico, que carece de un análisis multiescalar y de relación con otras categorías de análisis como es el tiempo.

El trabajo realizado y los resultados obtenidos por Evelyn Ortega y Joan Pagés nos da el punto de inicio para la Editorial del Número 79 de la Revista de Geografía Norte Grande. Tomando en consideración la preocupación de los Departamentos de Geografía en Chile producto de la baja matrícula de estudiantes en el año 2020, o nula en algunos casos, la educación geográfica apare- 
ce como un área donde es necesario poner especial atención. Considerando la baja preocupación que se ha tenido en Chile de la educación disciplinar y la pedagogía en la formación de los/las profesionales geógrafos/as, creemos que esto puede ser un área de análisis. Parte de esta despreocupación se encuentra en el aspecto teórico curricular, donde se observa un distanciamiento entre la teoría y el ejercicio profesional o investigativo de los/las futuros/as geógrafos/as.

Esto ha llevado a que el/la profesional geógrafo/a tenga una orientación técnica e instrumental en torno a la representación cartográfica digital y el uso de los Sistemas de Información Geográfica, lo cual ha llevado a una desorientación sobre las competencias que puede desarrollar en el ámbito público y privado. Al parecer, el interés que presentó la disciplina posterior al terremoto de 2010 y de la potencia para aportar en problemas relevantes para el país y el mundo, como los riesgos ambientales y el cambio climático, no se ha podido canalizar del todo en un proyecto común e integrador.

La Geografía aparece como una disciplina relevante en múltiples temas de interés coyuntural, como la problemática de la movilidad y las distancias en la pandemia, el proceso de descentralización, la discusión constitucional, los sistemas de evaluación ambiental y de riesgo o la gestión costera, entre otros tantos, pero esto no se ha reflejado en el interés por desenvolverse en el ámbito profesional.

Por ejemplo, el distanciamiento que se ha presentado entre el discurso político y la ciencia se puede evidenciar en el uso del concepto de territorio. En este caso, se ha ignorado por algunos proyectos políticos progresistas la dialéctica entre el territorio como sostén de la vida y como obstáculo simbólico. El obstáculo simbólico que el Estado colonial ha impuesto y producido a lo largo de la historia se ha ignorado muchas veces por dichos proyectos, los cuales siguen la reproducción de las mismas prácticas coloniales que se critican e incorporan en el discurso público.

Los trabajos de este número permiten sustentar la afirmación que, con evidencias científicas, se puede aportar en fortalecer la comprensión política del territorio y de su complejidad epistémica. Esto posibilitaría resignificar el ejercicio profesional de la geografía y de su relevancia para contribuir a la solución de problemáticas multiescalares.

En este sentido, el primer artículo de este número lleva por nombre "Movilidades, violencia y cuidados: la experiencia de mujeres bolivianas en los territorios chilenos de la Triple-frontera Andina" de las autoras Herminia Gonzalvez Torralbo, Menara Guizardi, Eleonora Lopez Contreras, nos presenta una revisión bibliográfica en las Ciencias Sociales sobre la experiencia femenina migrante boliviana a los territorios chilenos de la triple frontera andina. Estos antecedentes permiten comprender los resultados de investigaciones, develando la coexistencia espacial del patriarcado precolonial y colonial aymara que articulan los mandatos de género y la división sexual del trabajo.

El segundo trabajo de las/los autoras/es Trace Gale, Andrea Ednie, Andrés Adiego y Karen Beeftink denominado: "Cómo los visitantes y sus percepciones de los paisajes sonoros pueden mejorar la gestión colaborativa de las áreas protegidas", hace referencia a la percepción de los paisajes sonoros de la Reserva Nacional de Coyhaique que incluyeron datos demográficos y un ejercicio de audición del sonido ambiente, para aportar en la gestión de la reserva. La siguiente investigación lleva por título: "Prácticas Asociacionistas como estrategias de revitalización de 
la imagen de marca de un distrito turístico cultural. Caso de Barrio de Las Letras en Madrid y Barrio Italia en Santiago de Chile", de las autoras Stefania Pareti y Blanca García Henche, donde se presenta un estudio sobre el desarrollo de una marca de un destino turístico tomando en consideración las tradiciones y el patrimonio cultural del lugar, para crear un valor a los espacios y para la atracción de recursos.

"Permanencia y cambio en la percepción de los peligros urbanos" es el trabajo de las autoras Judith Ley García y Fabiola Maribel Denegri de Dios en el cual se exploran cambios y permanencias en la percepción de los peligros del entorno urbano de los habitantes de la ciudad de Mexicalí, México, entre los años 2011 - 2016. El siguiente artículo que acompaña este número que lleva por nombre "Percepción del riesgo ambiental en mega proyectos acuícolas. El caso de la comuna de Cobquecura en Chile" de las/los autores/as Paulina Alarcón, Álvaro Carrasco, César Salazar, Marcela Jaime y Cristina Martin, estudia el impacto de la actividad acuícola en la zona de Cobquecura en Chile. Se analizan las motivaciones de una comunidad rural para rechazar la instalación de una empresa acuícola en la zona, pese a las posibilidades de empleo que genera este tipo de empresas en la región sur-austral de Chile.

Continúa el número con el trabajo de "El regadío y su influencia en la regulación local de temperaturas en superficie en la citricultura mediterránea" de los autores José Antonio Albaladejo-García, Francisco Alcon, José Miguel Martínez-Paz. El objetivo de este trabajo es cuantificar y determinar los factores que explican el comportamiento de la Temperatura de la Superficie Terrestre (TS) en áreas de regadío, utilizando como caso de estudio el agroecosistema del cultivo de cítricos en regadío del Campo de Cartagena (Murcia, España). La investigación posterior de la autora Solène Rey-Coquais denominado como "De cobre, agua y glaciares en la metrópolis global. El nuevo papel de la mega minería en la gobernanza ambiental de Santiago de Chile" propone estudiar los impactos socioterritoriales del nuevo frente minero que avanza en pleno corazón de la Región Metropolitana de Santiago de Chile.

Un enfoque desde la Geografía legal es el que se presenta en el artículo de Chloé Nicolas Artero llamado "La construcción social de los mercados de agua en Chile: un enfoque desde la geografía legal" para entender la construcción social de los mercados de agua en la cuenca semiárida del río Elqui, desde la segundad mitad del siglo XX. Posteriormente, Paula Andrea Zapperi y Jorge Olcina analizan la aplicación de cartografía de riesgo de inundación en la planificación territorial en el trabajo denominado: “Cartografía de inundaciones en la planificación territorial. Estudio comparado entre Argentina y España".

Los/las autores/as Rogelio Baltazar Ascención, Carlos Alberto Mastachi-Loza, Adalberto Galindo Alcántara, Marivel Hernández Téllez, Rocio Becerril-Piña proponen, con "Metodología para la estimación de pérdidas económicas de cultivos de maíz siniestrados por inundaciones usando teledetección", una investigación en la que se determinaron las zonas inundadas de cultivo de maíz por medio de imágenes de satélite a fin de conocer las pérdidas económicas por inundaciones. En "Dinámica del empleo en sectores intensivos en uso del conocimiento en la Megalópolis del Valle de México, 2014-2018" los/la autores/a Iván Vilchis-Mata, Carlos Garrocho-Rangel y Tania Chávez-Soto utilizan el método Cambio-Participación Espacial (ACPE) para identificar el desarrollo de los territorios considerando el capital humano calificado. 
Un estudio epistemológico relativo al espacio/tiempo, sociedad/naturaleza y espacio/sociedad es lo que nos presentan Everaldo Batista da Costa y Vinicius Sodré Maluly en su trabajo "Geografía histórica y tiempo geográfico, concepto y superación de dicotomías". Este artículo tiene por objeto proponer el concepto de tiempo geográfico, constituyente epistémico y ente analítico de problemáticas espaciales transescalares y transtemporales operadas por la cartografía histórica. En el trabajo Ilamado "La cambiante interpretación de la Geografía española respecto a América Latina: paternalismo, hermandad e indiferencia", Rubén Lois González nos presenta una revisión bibliográfica para analizar la relación entre la geografía española con los estudios sobre América Latina.

Queremos finalizar la presentación de artículos de este número con el trabajo del académico Luis Daniel Santana Rivas, quien nos propone el trabajo "Notas sobre la subsunción de lo urbano al capital financiero: de las geografías de la financiarización a una agenda exploratoria", en el que sugiere realizar una crítica de la categoría de financiarización urbana tomando en consideración ciertos elementos comunes de las crisis urbanas, nombradas popularmente como 'estallidos sociales', tanto en Chile como más recientemente en Colombia. Por último encontraremos el trabajo de Evelyn Viviana Ortega Rocha y Joan Pagés Blanch, a quien realizamos un homenaje póstumo en esta editorial. 